\title{
L PLATERO VALENCIANO JACINTO FUENTES ESBRÍ Y EL CONFLICTO CON EL GREMIO DE PLATEROS DE MURCIA
}

IGNACIO JOSÉ GARCÍA ZAPATA ${ }^{1}$

Universidad de Murcia

ignaciojose.garcia@um.es

Resumen: El continuo movimiento de artistas en la España del siglo XVIII también se dejó sentir en los maestros dedicados al arte de la platería. Estas migraciones fueron bien notorias en el Reino de Murcia, a donde llegaron un nutrido número de plateros procedentes del vecino Reino de Valencia, entre otras localidades de Xàtiva. Dichos plateros, para poder ejercer su profesión en Murcia, debían cumplir y documentar una serie de requisitos, un proceso, que como documenta el caso de Jacinto Fuentes Esbrí, no estaba exento de polémica.

Palabras clave: Platería / Murcia / Xàtiva / Ordenanzas / Pleito.

Abstract: The continuous movement of artists in the eighteenth-century Spain was also felt in the artisans dedicated to the art of silversmithing. These migrations were well noticeable in the Kingdom of Murcia, where they arrived a large number of silversmiths from neighboring Kingdom of Valencia, among other locations of Xàtiva. These silversmiths, in order to practice their profession in Murcia, must fulfill certain requirements, a process that documents the case of Jacinto Fuentes Esbrí and was not exempt of controversy.

Key words: Silversmiths / Murcia / Xàtiva / Ordinances / Litigation.

La entrada al gremio de plateros de la ciudad de Murcia, y por tanto, el acceso a la libertad para poder ejercer el oficio, no estaba exento de problemas, cuando algún forastero intentaba entrar en el mismo. ${ }^{2}$ Los artistas de otros reinos despertaban un excesivo recelo entre los plateros murcianos, ${ }^{3}$ a pesar de que muchos de los mismos provenían de otros lugares. Es por ello que se les sometía a un control mucho más riguroso para permitirles trabajar en la ciudad. El capítulo veintiséis de las ordenanzas de 1738 dejaba claramente estipulado que aquellos artífices forasteros que quisieran poner tienda en Murcia debían de presentarse ante los veedores y examinarse. ${ }^{4}$ Sin embargo, el conflicto que Jacinto Fuentes Esbrí mantuvo a partir de 1734 con el gremio de plateros de Murcia, representados en los fieles contrastes Vicente Gálvez y José Grao, se desarrolló antes de la publicación de las ordenanzas, por lo que los criterios que dominaban la reglamentación eran los de 1717, mucho más ambiguos para esta cuestión. Este suceso constituye un perfecto ejemplo de ese control hacia los plateros que querían instalarse en Murcia, en especial para aquellos llegados de fuera del reino. Al tiempo, la abundante documentación generada por el pleito representa con gran detalle el amplio proce-

\footnotetext{
* Fecha de recepción: 15 de enero de 2017 / Fecha de aceptación: 13 de abril de 2017.

${ }^{1}$ Este estudio se ha llevado a cabo bajo la realización de la beca FPU otorgada por el Ministerio de Educación, Cultura y Deporte de España. Referencia: FPU014/00855.

2 Sobre la situación de los gremios de la ciudad de Murcia, ver: GARCíA ABELLÁN, Juan. Organización de los gremios en la Murcia del siglo XVIII y recopilación de ordenanzas. Murcia: Academia Alfonso X el Sabio, 1976.

${ }^{3}$ Está bien documentada la serie de dispuestas que los plateros murcianos mantuvieron con los plateros cordobeses a lo largo del siglo XVII, cuando los primeros demandaron al Concejo una mayor protección frente a la entrada de piezas cordobesas, llegando a abogar por la prohibición de que los plateros cordobeses pudieran ejercer y vender en la ciudad de Murcia. A.H.P.M. Not. 1368, fols. 48r-49v. AGÜERA ROS, José Carlos. Platería y Plateros seiscentistas en Murcia. Murcia: Universidad de Murcia, 2005, p. 42.

${ }^{4}$ Las ordenanzas del gremio de plateros de Murcia de 1738 han sido abordadas por el profesor Belda, ver: BELDA NAVARRO, Cristóbal. "Las ordenanzas de plateros del Reino de Murcia". Boletín de Arte, 1995, n 16, pp. 7-22.
} 


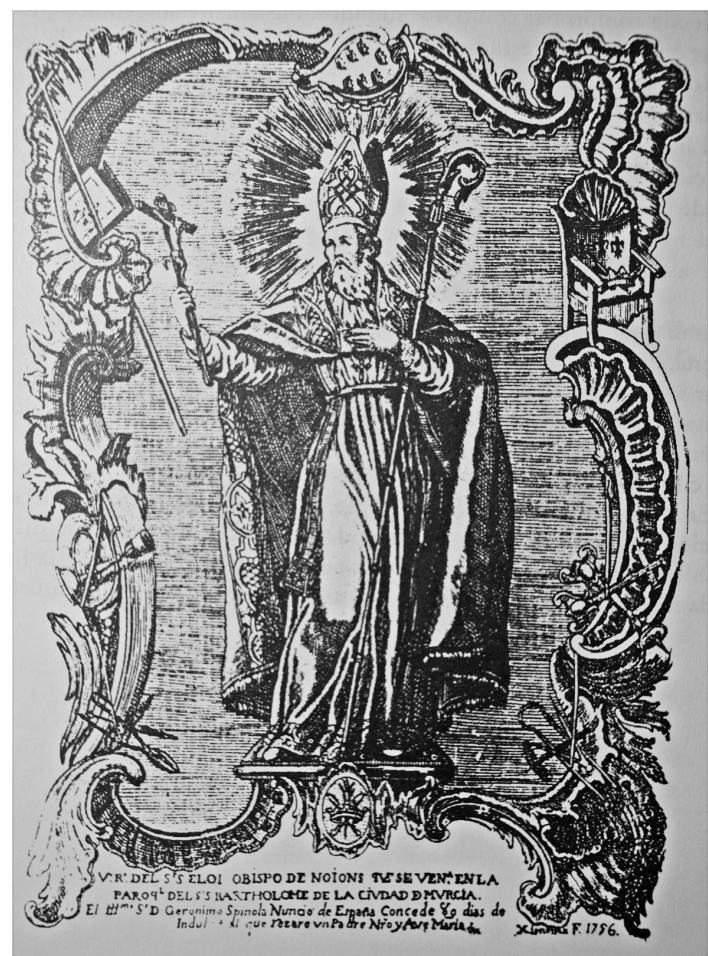

Fig. 1. Domingo Ximénez, San Eloy (1756), Estampa de las Reales Ordenanzas del Colegio y Congregacuón del Arte de Platero... de Murcia y su Reyno. Archivo Municipal de Murcia.

so vivido durante dos años, ante la negativa del gremio de que se examinara, derivando todo ello en un litigio de gran transcendencia para el arte de la platería española (Fig. 1).

En diciembre de 1734, Jacinto Fuentes Esbrí, natural de Xàtiva, y por tanto uno de los primeros miembros de la conocida y extensa saga de los Esbrí que se instaló en Murcia, solicitó ante el gremio de plateros ser examinado de maestro para poder instalar tienda en la ciudad. ${ }^{5}$ Con la petición adjuntó un extenso documento, fechado en 1730, dato importante a no olvidar, en el que se recogía la información necesaria para demostrar su limpieza de sangre. ${ }^{6}$ Las ordenanzas previas a 1738 , las de 1717, solo se conocen a consecuencia de este pleito, dado que a lo largo del mismo algunos de sus capítulos fueron la base para todo el conflicto. El joven platero, hizo de éstas los fundamentos de su defensa, valiéndose del tercer capítulo de las mismas, en el cual se indicaba que aquellos forasteros que quisieran poner tienda primero tenían que justificar ser cristiano viejo. Para cumplir debidamente con este requisito, Esbrí presentó un documento en el que incluía cuatro testimonios de personas vinculadas a él, entre familiares y vecinos. El primero de ellos era el de su padre, Vicente Fuentes, quien aseguraba que tanto él como su difunta esposa, Elena Esbrí, habían contraído matrimonio por la Santa Madre Iglesia Católica, y que los antepasados de ambos eran también cristianos limpios, sin vínculos judíos ni moros hasta donde él conocía. En su declaración afirmaba también que de su unión con Elena Esbrí habían nacido varios hijos, entre ellos un tal Vicente que recibió los hábitos de clérigo regular en Madrid, lo que confirmaba la limpieza. ${ }^{7}$ El platero de Xàtiva Ilamado Ignacio Juan, amigo de la familia, refrendaba los datos señalados por el padre, y añadía que dicha familia no había practicado nunca oficios viles, lo que demuestra cómo los plateros consideraban su oficio como un arte noble. ${ }^{8}$ Por último, el platero y alcalde mayor de Xàtiva, Constantino Fossar, y el vecino y amigo de la familia Francisco Capari, avalaban igualmente lo dicho. ${ }^{9}$

Jacinto Fuentes fue apoyado por tres plateros de la propia ciudad de Murcia, ${ }^{10}$ los cuáles, a través de su declaración jurada del dieciséis de diciembre de 1734, venían a respaldar con sus palabras el capítulo primero de las ordenanzas de 1717, el que expresaba literalmente que aquel en disposición de poner tienda debía haber practicado el arte por siete años, cinco como aprendiz y dos como oficial, todos ellos en casas de maestros ya aprobados, y después de ello debía hacer el examen conforme a lo indicado por los fieles de la platería, establecido por aquel entonces en la ejecución de una pieza de oro de cuatro onzas. ${ }^{11}$ El primer platero que lo amparó fue Pedro Martínez, quien dijo que lo había tenido en su taller como oficial durante un año y medio, y que lo había vis-

\footnotetext{
5 A.M.M. Leg. 4056, Doc. 79, fol. 11 r.

6 A.M.M. Leg. 4056, Doc. 79, fols. 1r-10r.

7 A.M.M. Leg. 4056, Doc. 79, fols. 1r-2v.

8 A.M.M. Leg. 4056, Doc. 79, fols. 2v-3r.

9 A.M.M. Leg. 4056, Doc. 79, fols. 5r-9r.

10 Acerca de los plateros murcianos del siglo XVIII, ver: SÁNCHEZ JARA, Diego. Orfebrería murciana. Madrid: Editora Nacional, 1950; CANDEL CRESPO, Francisco. Plateros en la Murcia del siglo XVIII. Murcia, 1999.

11 A.M.M. Leg. 4056, Doc. 79, fol. 21r.
} 
to al menos otros dos años empleado en otros obradores de la ciudad, especialmente en el del platero, también setabense, Andrés Donate. Por último, y aunque no era testigo de ello, había oído que Fuentes ejerció tanto en la villa de Xàtiva como en Madrid, y que en todos los lugares demostró una adecuada habilidad para el desempeño del quehacer artístico. ${ }^{12}$ Miguel Morote, platero de reconocido prestigio, precisó que le constaba que Jacinto había trabajado como oficial en Murcia durante cuatro años. Un año y medio tanto con Donate como con Martínez, lo que hacía un total de tres años, que se completaban con otro año que había estado en diferentes partes. Asimismo, le constaba que el referido había trabajado en su ciudad natal y en Madrid, y que era ducho en su oficio. ${ }^{13}$ Finalmente, Blas de Aguilar repitió lo mismo que los anteriores y verificaba que había estado cinco años como aprendiz en Xàtiva. ${ }^{14}$ A pesar de este aval de los plateros murcianos, el testimonio más contundente lo proporcionó Francisco Quinza, platero de Xàtiva, ${ }^{15}$ con quien Jacinto se había formado como aprendiz durante un periodo de cinco años, manifestando que durante ese tiempo había alcanzado las aptitudes necesarias para trabajar como maestro. ${ }^{16}$

Hasta este momento todo parecía que iba bien, sin embargo, como se desprende de la nueva solicitud de Jacinto Fuentes, los responsables del gremio no atendieron sus demandas, por lo que éste tuvo que enviar un nuevo escrito:

Jacinto Fuentes vezino de la Ciu de $S^{n}$ Phelipe; en la forma que mas aya Lugar = Digo que yo pedi se me Examinase del Arte de Plateros; a lo que semando Justificasse haver practicado dho Arte el tiempo que previene la Hordenanza, y Respecto de que e Estado trabajando Como Aprendiz y oficial por Espazio de Zinco años Con Franco quinza Maestro de Platero y Vezino de dha Ciu ${ }^{d}$ de $S^{n}$ Phelipe... ${ }^{17}$

La ausencia de una respuesta por parte de los fieles del arte llevó a intervenir al corregidor de la ciudad Diego de Velasco y Córdoba, quien valoró positivamente la documentación presentada por el aspirante, juzgando que cumplía con las orde- nanzas de los plateros. Por esta razón notificaba a los fieles contrastes que lo admitiesen a examen y que si tuvieran motivos para no hacerlo que lo indicasen en el periodo máximo de tres días. ${ }^{18} \mathrm{Y}$ así fue como, tras otorgar poder José Grao y Vicente Gálvez a Juan Serrano para que los defendiera y representara en la causa, los fieles expusieron los pretextos para impedir que se le examinase. El primero de ellos fue que no cumplía con lo dispuesto en las ordenanzas del buen gobierno del gremio, específicamente con el periodo de cinco años como aprendiz y dos como oficial, dado que para ejercer como aprendiz debió tener información acerca de su limpieza de sangre, exigida tanto en el caso del Reino de Valencia como en el de Murcia, lo cual no se había cumplido porque ésta fue presentada con fecha de 1730, y hasta 1734, data de solicitud de examen, no se alcanzaban ni tan siquiera los cinco años de aprendizaje, por lo que se ponía también en duda la veracidad de las palabras de Francisco Quinza. En lo que respecta al tiempo de oficial, los fieles estimaban que solo estaban probados unos veinte meses a lo sumo, por lo que tampoco satisfacía los dos años dispuestos en las ordenanzas. En última instancia, los maestros le requirieron un juramento claro y conciso en el que detallara el tiempo que estuvo como aprendiz y con qué artífices estuvo empleado en cada periodo, y si además era sabedor de que las ordenanzas valencianas no permitían que ningún mozo menor de doce años entrara de aprendiz, y que antes de entrar debía de presentar limpieza de sangre y el pago de la matrícula correspondiente, lo que servía para estar inscrito y por tanto legalizado, a la postre circunstancia transcendental que no se daba en el caso de Jacinto. ${ }^{19}$

\footnotetext{
...en atención a que por el espresado testimonio que llevo redarguido de falso no consta aunque fuese cierto haver sido algun tiempo aprendiz (...) combiene al dho de mis partes que dho Jacinto Fuentes Vajo de Juramento (...) Jure y declare clara y atentamente conforme a la Ley y Vajo supena que tiempo asido aprendiz y oficial de dho arte en que años lo asido y con que Maestros todo con claridad y distinción, y si sabe y le consta que según las ordenanzas
}

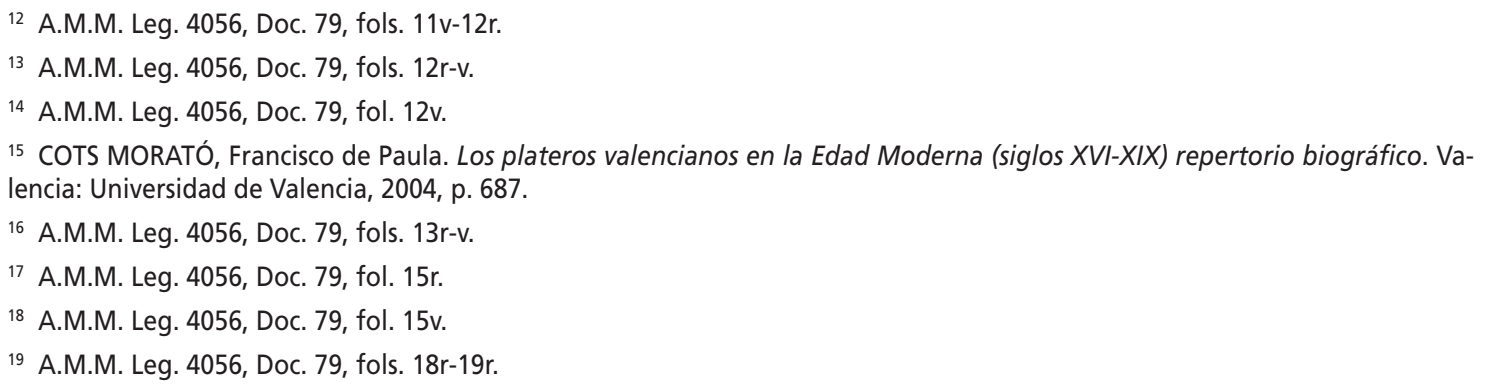


de la Ziud de Valencia que (...) ninguno puede entrar por aprendiz sin tener doze años de edad y hazer antes ynformazion de Limpiesa de Sangre, pagar cierta cantidad de peso y matricularse... ${ }^{20}$

La respuesta de Jacinto Fuentes no se hizo esperar, y el veintidós de enero de 1735 envió la información solicitada para que una vez valorada se le procediera a examinar, o en eso confiaba él, inconsciente del error que iba a cometer. En su explicación precisó que estuvo de aprendiz desde 1723 hasta 1728 con Francisco Quinza en su localidad, y que de 1728 hasta la solicitud del examen, 1734, ejerció como oficial con varios maestros, primero con Donate y Martínez en Murcia, luego con Carlos Llombart en Madrid, y de vuelta nuevamente con los mismos artistas anteriores. De igual manera ignoraba que las ordenanzas valencianas exigieran esa serie de requisitos determinados. ${ }^{21}$ En relación con el pago de la matrícula, eventualidad de suma gravedad, se defendió indicando que su padre pagó al fiel de Valencia los diez pesos para matricularse, pero que éste los retuvo, motivo por el que no aparece matriculado. ${ }^{22}$

Con posterioridad a esta respuesta, el Concejo incluyó en el auto los capítulos de las ordenanzas de 1717 que estaban relacionados con el caso. De este modo, José Royo, escribano del Rey y Mayor del Ayuntamiento, testificó que en el libro de ordenanzas del gobierno del arte de los plateros existían dos capítulos, el primero y el segundo, que por las indicaciones de los fieles eran necesarios ser observados en este asunto. Ambos capítulos eran un auténtico obstáculo a las aspiraciones de Jacinto Fuentes. El primero porque precisaba un periodo de tiempo, que vinculado con el segundo capítulo, él no había demostrado cumplir. Es decir, el hecho de haber presentado su expediente de limpieza de sangre con fecha de 1730, requisito previo para poder iniciarse en el proceso de aprendizaje como se indica en el segundo texto, imposibilitaba que en 1734 hubiera ejercido durante siete años. A tenor de estas contradicciones, Fuentes otorgó poderes al procurador José Vázquez para que lo defendiera. ${ }^{23}$
Que qualquiera que pretenda poner tienda de platería en esta Ziudad a de haver practicado el Arte siete años los cinco de Aprendiz, y los dos de oficial en casa de Maestros aprovados y después ha deser examinado por los fieles....24

Que no pueda exercer dho Arte por aprendiz ni oficial ni maestro ninguna persona que no sea Christiano Viejo (...) se prebiene que ningún Maestro reziba apreniz ni oficial sin veneplacito de todo el arte. ${ }^{25}$

Para, de algún modo, dar cumplimiento con los siete años requeridos por las ordenanzas, Jacinto sumó un nuevo documento relacionado con su limpieza de sangre cuya fecha era de 1728, ganando así los dos años que le faltaban para alcanzar los siete indicados. En este nuevo texto, los setabenses Onofre Navarro, maestro de herrero, y Pedro Juan Canzor, maestro de carpintero, confirmaba la buena estirpe de los antepasados del protagonista. ${ }^{26}$

A finales de enero, Vázquez en defensa de su representado, una vez vista y aportada la documentación por su cliente, instó a los fieles del arte de Murcia a que examinasen a Jacinto Fuentes por haber demostrado su ejercicio como oficial durante un tiempo superior al solicitado en las ordenanzas. Este requisito lo probó en razón del documento de limpieza de sangre que en 1728 presentó a Andrés Donate para poder ejercer en su tienda como oficial, y que el de 1730 solo se hizo para darle mayor formalidad. Por otro lado, la defensa consideraba que las acusaciones vertidas sobre Esbrí acerca de que no había estado cinco años como aprendiz eran despreciables, pues los testigos así lo atestiguaban. Por último, centró todos sus esfuerzos en el capítulo tercero de las ordenanzas, mediante el cual él intentó tener éxito en su propósito de examinarse. Este capítulo precisaba que si un oficial forastero -por ello hacía tanto hincapié en que había ejercido de oficial- quería poner tienda en la ciudad, solo tenía que presentar limpieza de sangre, por lo que consideraba ocioso el querer averiguar acerca de su aprendizaje. Cerraba la intervención el apoderado con una alusión un tanto desafiante, dado que si Jacinto quería ser examinado en Murcia, por qué se de-

20 A.M.M. Leg. 4056, Doc. 79, fol. 19r.

${ }^{21}$ Acerca de la organización y el desarrollo del gremio de platero de Valencia, ver: GARCÍA CANTÚS, Dolores. El gremio de plateros de Valencia en los siglos XVIII y XIX. Valencia: Ayuntamiento de Valencia, 1985.

22 A.M.M. Leg. 4056, Doc. 79, fols. 19v-20v.

23 A.M.M. Leg. 4056, Doc. 79, fol. 23r.

24 A.M.M. Leg. 4056, Doc. 79, fol. 21 r.

25 A.M.M. Leg. 4056, Doc. 79, fol. 21v.

26 A.M.M. Leg. 4056, Doc. 79, fols. 24r-25v. 
bían de seguir las ordenanzas de Valencia. ${ }^{27}$ En definitiva, lo que procuraba esta parte era centrar toda la atención en el tercer capítulo de las ordenanzas murcianas, el cual no decía nada de las fechas necesarias, solo de la limpieza de sangre y de haber sido oficial bajo el mandato de algún maestro, circunstancia que también demostraba con mucho ahínco. A su vez obviaba los requisitos de las valencianas, dado que la solicitud era por Murcia.

Que si hubiese algun oficial forastero y pretendiese poner tienda en esta Ciudad, a trabajar como tal oficial en casa del algun Maestro, no se le ha de permitir que la ejecute sin que primero Justifique ser christiano viejo (...) y después se ha de examinar...28

A pesar de que a priori los argumentos de Fuentes parecían poderosos para no continuar con el litigio, sobre todo en lo que respecta a ese capítulo tercero de las ordenanzas murcianas, los fieles del gremio, quizás presionados, como se verá más adelante, no cesaron en su postura y volvieron a pronunciarse en contra de la nueva solicitud de examen. Juan Serrano, por parte de los fieles, volvió a dirigir las miradas hacia el título uno de la citada normativa, por el que cualquiera con intención de instalar tienda debía de cumplir con los requisitos de cinco años como aprendiz y dos como oficial, los cuales, sobre todo como aprendiz, no tenía Fuentes justificados, dado que los testigos ofrecidos por su parte no eran de crédito. ${ }^{29}$ Además, contaban con un documento firmado por Francisco Antonio Ferriz, miembro de la Real Junta General de Comercio y Moneda con delegación en Valencia, quien dio fe y verdadero testimonio de dos aspectos vitales. El primero de ellos confirmaba que Jacinto Fuentes no aparecía en el libro de aprendices de Valencia junto a ningún maestro platero, ni tan siquiera con Francisco Quinza, con quien supuestamente había pasado cinco años. En segundo lugar, y mucho más importante, resultaba que Quinza se examinó en 1724, un año después de que supuestamente Esbrí entrará a trabajar en su taller, lo cual suponía una infracción dado que nadie podía admitir aprendiz sin estar examinado y mucho menos tener tienda propia. ${ }^{30}$ Este dato reducía, siempre que fuera verdad, a cuatro años el tiempo de aprendizaje de Jacinto, lo que se presentaba como un nuevo escollo para solicitar el examen. ${ }^{31}$ Además, los fieles, consideraron esta aportación suficiente como para que se dictase sentencia y se le obligara a correr con el pago de las costas. ${ }^{32}$

Aunque el curso del proceso iba contra la voluntad de Fuentes, éste no se echó atrás y volvió a la carga recurriendo a nuevos argumentos que no hacían sino enredar más la situación, diluyéndola en el tiempo y volviéndola aún más complicada. Él era consciente de que su baza principal era recurrir e insistir en lo indicando en el tercer capítulo de las ordenanzas, lo que a su parecer le daba vía libre para examinarse, dado que como forasteros los dos primeros capítulos no le afectaban. Ante las denuncias de que las declaraciones aportadas por él eran extrajudiciales, Jacinto Fuentes indicó que no estaba estipulado cómo debían ser realizadas, de modo que tenían que ser consideradas óptimas. En relación con el dato ofrecido por la Junta de Comercio, solo pudo decir que él había empezado como aprendiz en torno a 1723, pero que no podía precisar un día y un mes. En definitiva, por todo ello, abogaba que se cumpliera con el dictamen del 14 de enero que veía razonables sus propósitos y le facultaba para examinarse. ${ }^{33}$ Hasta aquí todo en líneas generales era una reiteración por su parte, sin embargo iba a abrir dos nuevas líneas de debate. La primera de ellas recriminaba que todo el conflicto estaba generado por su antiguo maestro Andrés Donate, quien no había aceptado que Jacinto Fuentes hubiera rechazado ejercer con él como oficial en su taller, y que por ello, como una clara venganza, estaba presionando para que no se le examinara. A esto añadió que a los maestros Andrés Donate, Nicolás Tarragón y Antonio Jiménez, todos ellos forasteros, solo se les solicitó la limpieza de sangre, y por tanto con ellos sí se aplicó el artículo tercero. ${ }^{34}$

La extrema gravedad y las proporciones del conflicto conllevaron la realización de una junta del

\footnotetext{
27 A.M.M. Leg. 4056, Doc. 79, fols. 26r-27v.

28 A.M.M. Leg. 4056, Doc. 79, fol. 26 r.

29 A.M.M. Leg. 4056, Doc. 79, fols. 30r-31v.

${ }^{30}$ Sobre el examen para el acceso al arte de la platería en Valencia, ver: COTS MORATÓ, Francisco de Paula. El examen de maestría en el arte de plateros de Valencia (1505-1882). Valencia: Ayuntamiento de Valencia, 2004.

31 A.M.M. Leg. 4056, Doc. 79, fols. 32r-v.

32 A.M.M. Leg. 4056, Doc. 79 , fol. 33v.

33 A.M.M. Leg. 4056, Doc. 79, fols. 38r-39r.

${ }^{34}$ A.M.M. Leg. 4056, Doc. 79, fols. 38r-v.
} 
gremio el 17 de enero, en las que se dieron cita la mayoría de los plateros de la ciudad para debatir la postura de la congregación. En ella se respaldaron las actuaciones de los fieles, permitiéndoles financiar los gastos del proceso con el dinero del arca, dado que no estaba demostrado que hubiera estado cinco años de aprendiz. ${ }^{35}$ Gracias a documentos posteriores se tiene constancia de que la junta fue problemática, en tanto que Nicolás Martínez salió en defensa de Esbrí, solicitando que a pesar de lo indicado por todo el mundo se le debía de examinar. Igualmente, aunque de forma más vehemente, intervino Pedro Martínez, que luego resultó ser el platero que daba cobijo a Jacinto Fuentes, quien se encaró con Alejandro Vigueras, a quien llegó a espetarle "...que siempre saltava como granizo en albarda, y que todavía avia de oler mal la dependencia...". ${ }^{36}$ Sin embargo, y a pesar de la protesta de Nicolás Martínez, incluso con el abandono de la junta, y del grave incidente con el otro Martínez, ambos plateros, al parecer aconsejados, acabaron aceptando la resolución de la junta, a la que también dijeron no estar de acuerdo con que las costas se financiasen con dinero del caudal común. ${ }^{37}$

Con el respaldo del gremio, Vicente Gálvez y José Grao, no se amilanaron ante la incansable postura de Fuentes, a quien recordaron el necesario cumplimiento del primer capítulo, dado que el tercero, del que se servía el aspirante, no derogaba ni entraba en contradicción con el primero. Volvieron a insistir en la obligación de cumplir con las ordenanzas y a recalcar que no estaba demostrado su periodo como aprendiz tanto por tiempo como por no estar matriculado. A este respecto incluyeron la documentación relativa a los procesos de examen de Agustín Martínez, de Murcia, y de Pascual Pacheco, natural de Orihuela que había pedido examinarse en Murcia, y por lo tanto en la misma situación que Jacinto Fuentes, aunque con toda la documentación en regla. Ante las graves acusaciones acerca de la influencia que sobre ellos estaba teniendo Donate, apuntaron que las insinuaciones vertidas eran falsas, dado que la ciudad cuenta con un amplio número de oficiales válidos que habrían podido cubrir las necesidades del dicho Donate. Finalmente, se volvió a pedir responsabilidades con el pago del proceso por faltar repetidamente a la verdad. ${ }^{38}$
Después de unas semanas de reflexión, solicitadas por el apoderado de los fieles, éstos no se replantearon su posición sino que arremetieron con un mayor número de argumentos, en su mayoría procedentes de los maestros plateros de la propia ciudad natal de Jacinto Fuentes, lo que se presentaba como el golpe definitivo. Así, a finales de marzo, recibieron noticias acerca de Fuentes y su formación en los siguientes términos:

\begin{abstract}
...y aora nuevamente ha llegado a noticia demis partes, y asi lo puso en sus animas, el que dho Jacinto fuente, hijo de Vicente fuentes, dio principio a aprendiz de dho arte de platero como aprendiz en casa de Jacinto fozes en la Ciudad de Gandia de dho Reino, donde estubo muy pocos dias, y desde allí se paso a la de fran. Quinza en la de San Phelipe; y aviendole recombenido Ygnacio Juan (...) para que se matriculase en la de Valencia, porque sin estarlo no le podía permitir el que fuese tal aprenzi, ni reconozerle por tal, se ausento de la expresada de San Phelipe, y aunque después volvió a ella, lo mas del tiempo se estaba paseando sin asistir en Casa de Platero alguno; y aunque despues quiso continuar en casa de algunos maestros, haciendo la visita que haze el arte de dha Ciudad de Valencia, y dichole que Como pretendía aprender el arte sin estar matriculado por aprendiz en ellas, respondio que donde avia aprendido, como tal aprendiz, era en esta de Murcia, con cuio motivo le concedio la Visita dos meses de termino para que en ello lo pudiese justificar, lo que no hizo en manera alguno, y por ello, no se le ha tenido ni tienen en dha Ciudad de San Phelipe por tal aprendiz ni oficial del arte...39
\end{abstract}

En vistas de todo ello, le dieron un tiempo para justificarlo con documentos, los cuáles nunca llegó a aportar. En conclusión, los fieles dijeron que ni en su ciudad natal se le tenía por aprendiz ni oficial de platero. Además solicitaron más interrogatorios con otros testigos tanto de Murcia como de la ciudad valenciana.

Con esta instrucción se procedió a interrogar a una serie de plateros murcianos, a los cuales se les sometía a cuatro preguntas. La primera acerca de si conocían el litigio y su desarrollo. La segunda sobre si sabían qué tiempo de oficio ha tenido Jacinto. La tercera, curiosamente, preguntaba sobre el conflicto vivido en la junta del mes de enero, y, finalmente, la cuarta era un trámite acerca de si decían la verdad y de si podían publicarse sus res-

\footnotetext{
35 A.M.M. Leg. 4056, Doc. 79, fols. 40r-41v.

${ }^{36}$ A.M.M. Leg. 4056, Doc. 79, fol. $45 \mathrm{v}$.

${ }^{37}$ A.M.M. Leg. 4056, Doc. 79, fols. 45v-46r.

38 A.M.M. Leg. 4056, Doc. 79, fols. 42r-45r.

${ }^{39}$ A.M.M. Leg. 4056, Doc. 79, fols. 48r-v.
} 
puestas. ${ }^{40}$ Los elegidos fueron Nicolás Tarragón, Ignacio Casa, Alejandro y Alonso Vigueras, Eugenio García Puerta, Francisco Martínez Cano, José Jiménez, Benito Franco, Juan Antonio Guerrero y Nicolás García Taybilla. A grandes rasgos, ninguno se salió de la ruta establecida por el gremio en la junta, dado que todos respondieron conocer el caso, haber visto a Jacinto Fuentes trabajar unos doce meses con Donate y otros ocho con Martínez, salvo pequeñas matizaciones. También narraron del mismo modo el incidente de la reunión y no temían a que sus respuestas se publicasen. ${ }^{41}$ Los interrogatorios fueron presentados ante Diego de Velasco y Córdoba, fiscal de justicia mayor, quien dio veinte días a la parte contraria para presentar alegaciones, a la vez que autorizaba nuevos interrogatorios a los plateros de Xàtiva, los cuales se llevaron a cabo en abril. ${ }^{42} \mathrm{~A}$ José Gozalbo le constaba que Jacinto Fuentes había iniciado su formación en Gandía, pasando después cuatro años con Quinza, salvo un periodo en el que se ausentó cuando Ignacio Juan le indicó que debía viajar a Valencia a matricularse. Después conocía que había sido oficial en el obrador de Francisco Sanmartín y en otros, todos de Xàtiva. ${ }^{43}$ Uno de los interrogatorios más importantes fue el que se tuvo con Francisco Quinza, con quien Fuente decía haberse instruido cinco años. Éste respondió que ciertamente fueron cuatro, evidentemente no podía decir cinco, dado que si no incurría en una sanción por haberlo acogido antes de estar declarado maestro. Confirmó que el por entonces aprendiz marchó a Valencia para matricularse, y que él, al enterarse con el paso de los años de que no lo llegó a hacer, lo echó. Ratificó que tras un periodo en varios talleres de la villa, y después de no atender a las peticiones del gremio valenciano acerca de su formación, se marchó a Murcia. En fin, no le puso las cosas fáciles al pretendiente, lo que de algún modo intentó suavizar al final, alegando que el responsable de todo era el padre de Jacinto, Vicente Fuentes, quien no le había asistido. ${ }^{44}$ Tanto Antonio como Jacinto Llaudens dije- ron lo mismo, incluyendo el taller de Xàtiva de Constantino Fossar como otro donde el protagonista trabajó. ${ }^{45}$

Los defensores de Fuentes intentaron contrarrestar todo lo que se cernía sobre él con nuevos testigos, a los cuales les formularon las siguientes preguntas. Primero el trámite de saber si estaban al tanto del litigio y su desarrollo, después si conocían cuánto tiempo estuvo el implicado en el taller de Quinza, así como en una tercera pregunta si sabían que hubiese sido oficial en otros negocios. En cuarto lugar se volvió a la carga con el trato desigual ofrecido tiempo antes a Donate, Tarragón y Jiménez, y se preguntaba a los testigos si corroboraban que a estos solo se les pidió cumplir con el tercer título de las ordenanzas. Para finalizar, y antes de preguntarles por la veracidad de sus respuestas, les pidieron que dieran su opinión acerca de si todo esto era propiciado por las presiones que Donate estaba ejerciendo sobre los fieles de Murcia. ${ }^{46}$ El primero en intervenir fue Nicolás Martínez, platero cuñado de Pedro Martínez, con quien se hospedaba Jacinto Fuentes. Cinco años de aprendiz son los que había escuchado que el susodicho había estado, así como que de 1728 a 1734 trabajó como oficial con Donate y Martínez, viajando algún tiempo a Madrid. A la cuarta pregunta respondió que a dichos artistas forasteros solo se les exigió el cumplimiento del tercer artículo, limpieza de sangre y su tiempo de oficial. Finalmente, ante la cuestión de Donate, dijo que le constaba cómo éste iba mucho a casa de los fieles Vicente Gálvez y José Grao, ${ }^{47}$ ¿quizás a presionarles? Agustín Pérez, maestro platero, además de ratificar lo dicho por Nicolás Martínez, aportó un nuevo dato, relativo a cómo Donate un día insistió mucho al artífice Blas de Aguilar para que éste actuara contra Esbrí. ${ }^{48}$ Otra serie de personajes también intervinieron, como un tal Pablo de Xàtiva, vecino y amigo de Jacinto que avalaba las fechas dadas por su amigo. ${ }^{49}$ Juan Bautista, torcedor de seda de origen setabense pero resi-

\footnotetext{
40 A.M.M. Leg. 4056, Doc. 79, fols. 54r-v.

41 A.M.M. Leg. 4056, Doc. 79, fols. 55r-71r.

42 A.M.M. Leg. 4056, Doc. 79, fols. 78r-79v.

43 A.M.M. Leg. 4056, Doc. 79, fols. 80r-81r.

44 A.M.M. Leg. 4056, Doc. 79, fols. 81r-83r.

45 A.M.M. Leg. 4056, Doc. 79, fols. 83r-85r.

46 A.M.M. Leg. 4056, Doc. 79, fols. 86r-v.

47 A.M.M. Leg. 4056, Doc. 79, fols. 87r-89r.

48 A.M.M. Leg. 4056, Doc. 79, fols. 89v-92r.

49 A.M.M. Leg. 4056, Doc. 79, fols. 92v-93v.
} 
dente en Murcia indicó lo mismo, al igual que Pedro Aledo y Salvador y Antonio Ramos, vecinos también de Murcia. ${ }^{50}$

Después de unos meses, en noviembre del mismo año de 1735, los fieles volvieron a arremeter contra la falta de verdad con que había obrado Fuentes, en tanto que era imposible que ejerciera como aprendiz con Quinza si éste no era maestro hasta el 1724, como él mismo había precisado. Asimismo, restaban importancia a las opiniones de Nicolás y Pedro Martínez, pues se conocía que ambos eran sus íntimos amigos. Y con respecto a Donate, indicaron que no era cierto que éste ejerciera ningún tipo de presión, ya que ellos cumplían con las obligaciones que estaban escritas en las ordenanzas. ${ }^{51}$

Con todos estos datos, informes y testimonios, y tras la ausencia de respuesta por parte del aspirante, Juan Francisco de Luján y Arce, Corregidor de Justicia Mayor de Murcia, sentenció que Jacinto Fuentes Esbrí no había probado los requisitos necesarios para procedérsele a realizar el examen afín de adquirir la maestría de platero, mientras que los fieles del gremio de plateros de Murcia sí habían justificado sus alegatos en el incumplimiento de los requisitos de las ordenanzas. Por tanto, no había de ser examinado y además debía de correr con el pago de las costas de la causa. ${ }^{52}$ La sentencia fue apelada a mediados de diciembre, basando la reclamación en el agravio que había recibido Fuentes, de modo que solicitaban su subida a la Real Chancillería de Granada, ${ }^{53}$ apelación que según los fieles era excesiva e inadecuada, dado que el asunto correspondía ser tratado en todo caso por la Real Junta de Comercio y Moneda, la misma que ya había intervenido en favor del gremio. ${ }^{54}$ Durante las siguientes semanas no se volvió a saber nada de la parte de Fuentes, que no respondía a las notificaciones que le interpelaban a mejorar su apelación, de modo que a co- mienzos de 1736, el Corregido dio la sentencia definitiva al pago de las costas, que fueron estipuladas en doscientos noventa y nueve reales..$^{55}$

Ahora sí que parecía que todo había finalizado, pero nada más lejos de la realidad, ya que Jacinto Fuentes desapareció de la ciudad, y no se le conocía el paradero, por lo que se solicitó el embargo de sus bienes para cubrir el pago al que había sido sentenciado. ${ }^{56}$ En junio fue finalmente localizado y apresado, ingresando en la Cárcel Real de la ciudad. ${ }^{57}$ Tras ser puesto bajo control del Alcaide, Fuentes hizo una declaración en la cual se lamentaba por estar preso, sin familia ni amigos que le ayudaran en la ciudad, y hacía un resumen de todo lo sucedido, hasta que se marchó de la ciudad sin saber que había sido condenado, y que al tener constancia volvió para cumplir sus obligaciones, pero que no tenía medios para enfrentarlas. Por ello, ofreció su trabajo para pagarlas, implorando a la vez su libertad por ser desproporcionado su encierro solo por no haber pagado. En última instancia, pedía que valorasen los bienes que aún le quedaban para que comprobasen si les servían para cubrir el pago, y así se le liberase. ${ }^{58}$ El 28 de julio se dictó su libertad, y tras la decisión del gremio, Esbrí entró como oficial a servicio de Nicolás Martínez, quien debía retenerle todos los meses el sueldo hasta que satisficiera la cantidad estipulada por el proceso. ${ }^{59}$

Tuvo que enderezar su rumbo el platero valenciano, puesto que en 1737 contrajo matrimonio con María Teresa, hija de Antonio Mariscotti, uno de los maestros más reconocidos del momento, con quien tuvo cinco hijos. En 1757, en el Catastro del Marqués de Ensenada, aparecía como maestro platero, casado y con cuarenta y cinco años, con tres hijos menores de dieciocho años y dos aprendices. ${ }^{60}$ La muerte le llegó en 1762 , enterrándose en la parroquia de los plateros, San Bartolomé. ${ }^{61}$

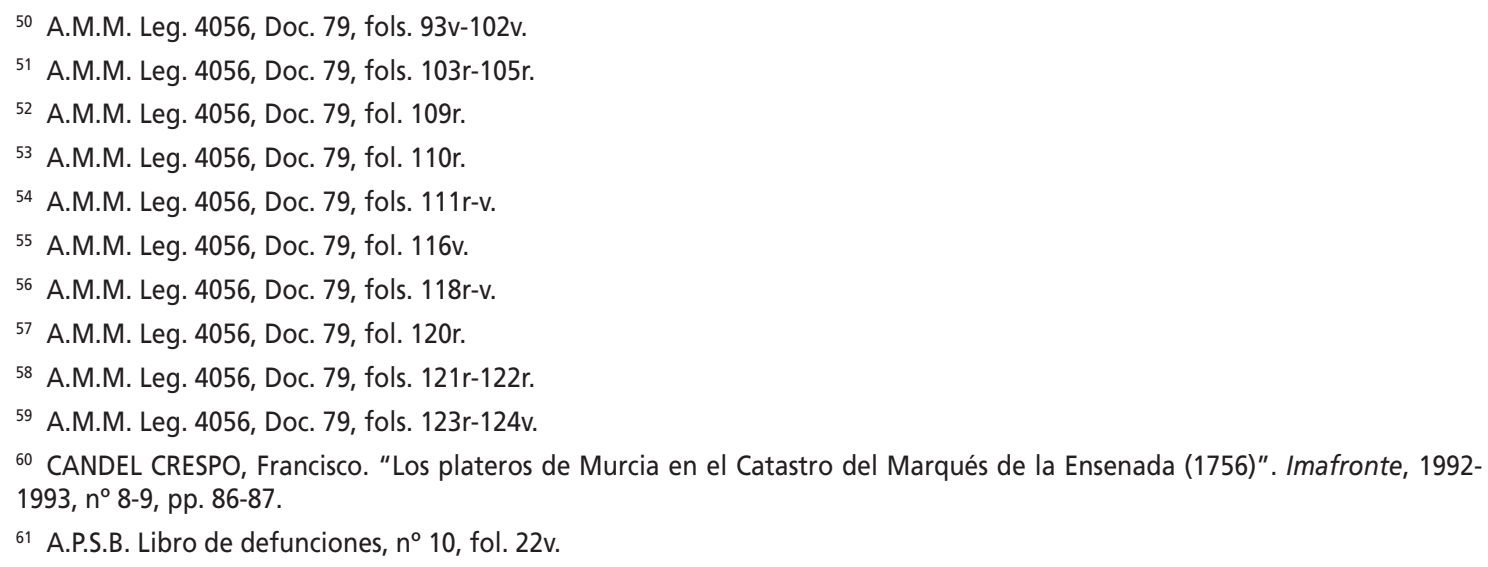


El caso de Jacinto Fuentes no fue el único conflicto relacionado con el acceso a la maestría en la ciudad de Murcia. Poco después, Vicente Rovira, pidió que fuese confirmado maestro, presentando para ello testimonios otorgados por un escribano valenciano. En ellos se especificaba que había obtenido el título, en Valencia, en 1734, pasando posteriormente por Orihuela, su ciudad natal, donde fue fiel contraste. En Murcia, sus aspiraciones se vieron truncadas por la actuación de Antonio Jiménez y Nicolás Martínez, este último ahora en una situación inversa, con una postura muy distinta a la que había tenido con Fuentes. Ellos argumentaban que mientras no se aprobasen las nuevas ordenanzas no se debía de examinar a ninguna persona. Una opinión que fue contradicha por el regidor Manresa, quien dio conforme a lo establecido en las ordenanzas de 1717 , concretamente en la tercera, los permisos para ser examinado. Una vez presentada la limpieza de sangre, se le aceptó el trámite, aunque su examen se retrasó hasta 1748, y a partir de entonces ejerció en la ciudad. ${ }^{62}$ En definitiva, el caso de Rovira puso de manifiesto la reticencia que había acerca de los plateros llegados de otras tierras, algo habitual en todas las ciudades, como también ocurrió con el murciano Antonio Morote, que le hicieron examinarse de nuevo los miembros del arte de la platería de Valencia.

\section{Bibliografía:}

AGÜERA ROS, José Carlos. Platería y Plateros seiscentistas en Murcia. Murcia: Universidad de Murcia 2005.

BELDA NAVARRO, Cristóbal. "Las ordenanzas de plateros del Reino de Murcia". Boletín de Arte, 1995, n 16 , pp. 7-22.

CANDEL CRESPO, Francisco. "Los plateros de Murcia en el Catastro del Marqués de la Ensenada (1756)". Imafronte, 1992-1993, n 8-9, pp. 86-87.

CANDEL CRESPO, Francisco. Plateros en la Murcia del siglo XVIII. Murcia, 1999.

COTS MORATÓ, Francisco de Paula. Los plateros valencianos en la Edad Moderna (siglos XVI-XIX) repertorio biográfico. Valencia: Universidad de Valencia, 2004.

COTS MORATÓ, Francisco de Paula. El examen de maestría en el arte de plateros de Valencia (1505-1882). Valencia: Ayuntamiento de Valencia, 2004.

GARCÍA ABELLÁN, Juan. Organización de los gremios en la Murcia del siglo XVIII y recopilación de ordenanzas. Murcia: Academia Alfonso X el Sabio, 1976.

GARCÍA CANTÚS, Dolores. El gremio de plateros de Valencia en los siglos XVIII y XIX. Valencia: Ayuntamiento de Valencia, 1985.

PEÑA VELASCO, Concepción. "El platero Bernabé Vallejos, sus relaciones familiares con Francisco Salzillo y algunas incidencias del gremio a comienzos del siglo XVIII". En RIVAS CARMONA, Jesús (coord.). Estudios de Platería: San Eloy 2001. Murcia: Universidad de Murcia, 2001, pp. 183-198.

SÁNCHEZ JARA, Diego. Orfebrería murciana. Madrid: Editora Nacional, 1950.

62 PEÑA VELASCO, Concepción. "El platero Bernabé Vallejos, sus relaciones familiares con Francisco Salzillo y algunas incidencias del gremio a comienzos del siglo XVIII". En RIVAS CARMONA, Jesús (coord.). Estudios de Platería: San Eloy 2001. Murcia: Universidad de Murcia, 2001, p. 189. A.M.M. Actas Capitulares 1737, fol. 223r y 1738, fols. 18v-19r. 
